\title{
Anal intraepithelial neoplasia in an inflammatory cloacogenic polyp
}

\author{
I M Hanson, G R Armstrong
}

\begin{abstract}
A rare case of anal intraepithelial neoplasia arising in an inflammatory cloacogenic polyp is reported. While the occurrence of neoplasia complicating benign anal conditions is recognised, this case re-emphasises the need for careful histological examination of all perianal lesions.

(f Clin Pathol 1999;52:393-394)
\end{abstract}

Keywords: cloacogenic polyp; mucosal prolapse; anal intraepithelial neoplasia

Inflammatory cloacogenic polyps of the anal transitional zone were first described in $1981 .{ }^{1}$ The term "mucosal prolapse syndrome" was proposed by du Boulay et al in $1983^{2}$ to describe the characteristic features of these lesions, solitary rectal ulcers and related disorders, which are thought to share mucosal prolapse as the underlying pathogenic mechanism. While inflammatory cloacogenic polyps are often associated with mucosal prolapse (hence the variable terminology in published reports), Saul et al suggested that these polyps may develop under different circumstances, with mucosal injury as the underlying cause. ${ }^{3}$ These investigators reported what we believe to be the

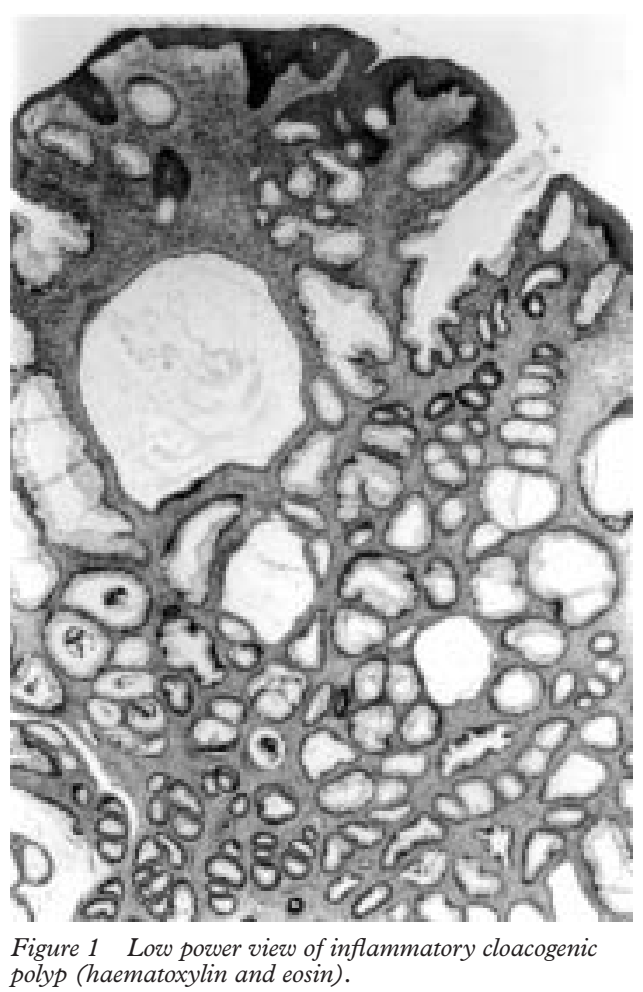

only previous case of anal intraepithelial neoplasia within an inflammatory cloacogenic polyp. ${ }^{3}$

In this report we describe another more florid case of anal intraepithelial neoplasia arising within an inflammatory cloacogenic polyp.

\section{Case report}

A 34 year old woman presented with a two month history of recurrent rectal bleeding and passage of mucus. She had suffered similar symptoms episodically over the previous six years, and had had four endoscopic resections of polyps from just above the dentate line of the anal canal from various circumferential positions. These had been diagnosed histologically as inflammatory in nature, showing features of the mucosal prolapse syndrome. In 1991, colonoscopy as far as the caecum had been otherwise normal.

At sigmoidoscopy this time, a soft fleshy polyp was visualised posteriorly and resected. No other anorectal abnormality was seen.

\section{GROSS EXAMINATION}

The polyp measured $0.7 \mathrm{~cm}$ in its greatest axis, and was brown and soft in consistency.

\section{MICROSCOPIC EXAMINATION}

Histologically, the polyp had the typical architectural features of an inflammatory cloacogenic polyp (fig 1). Within the stroma, there was central splaying of fibres of the muscularis mucosae and fibromuscular obliteration of the lamina propria. Large intestinal type glands were irregularly placed peripherally, many distorted and branching, some cystically dilated and hyperplastic. There was a moderate active chronic inflammatory cell infiltrate with focal superficial ulceration. In addition, much of the surface epithelium of the polyp was covered by stratified squamous epithelium, in which there was moderate and severe squamous intraepithelial neoplasia (fig 2). This dysplastic epithelium extended into some of the superficial large intestinal glands but there was no evidence of invasive neoplasia. There was overlying parakeratosis, many dyskeratotic cells, occasional multinucleate forms, and focal koilocytic atypia, suggestive of human papillomavirus (HPV) infection. Non-polypoidal mucosa was not submitted, although at one diathermied margin there was some anal transitional zone tissue.

A cervical smear taken following these histological findings has shown features of HPV infection and mild squamous dyskaryosis. 


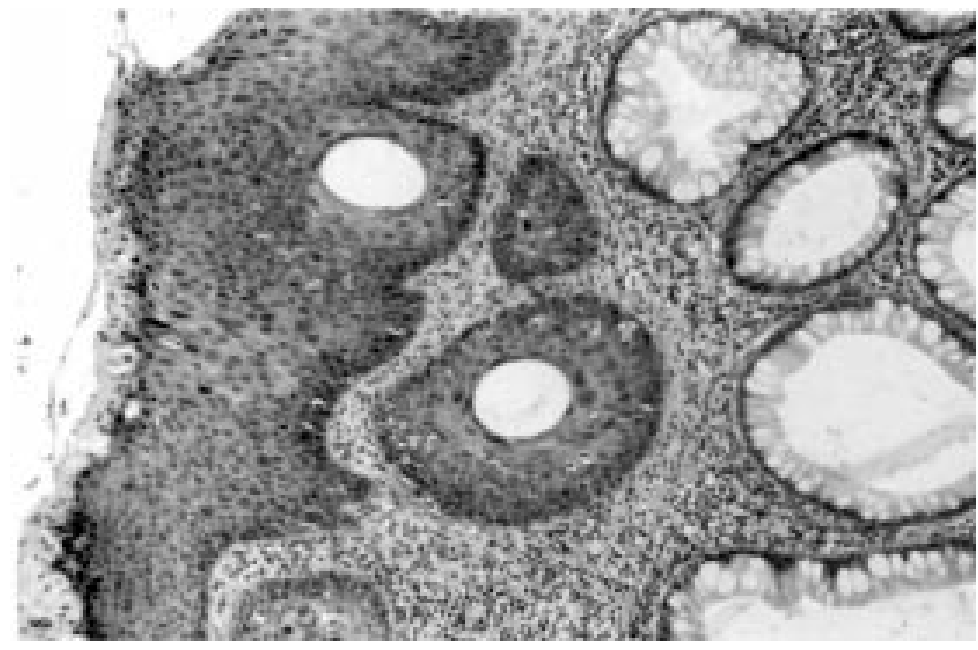

Figure 2 Surface epithelium at high power with features of high grade anal intraepithelial neoplasia (haematoxylin and eosin).

\section{Discussion}

The presence of squamous epithelium with HPV related features in an inflammatory cloacogenic polyp has been reported only once before, ${ }^{3}$ and in that case foci of mild and moderate squamous dysplasia were noted. Our case represents a second, more florid example of this probably coincidental association.

The association of benign anal lesions with anal neoplasia has been investigated in several studies. In a large population based Danish study, ${ }^{4} 0.03 \%$ of patients receiving treatment for fissures, fistulas, abscesses, and haemorrhoids subsequently developed anal squamous cell carcinoma, and the association was not thought to be causal. The incidental finding of anal intraepithelial neoplasia within haemorrhoidal specimens was studied by Foust et al. ${ }^{5}$ Nineteen cases were identified over a 22 year period, frequently associated with HPV infection as detected by in situ hybridisation. Recurrence was uncommon (one case) and haemorrhoidectomy curative after a mean six year follow up.

Although the natural history of anal intraepithelial neoplasia has yet to be fully defined, it shows similarities with cervical intraepithelial neoplasia, being associated with HPV infection and multifocal female genital intraepithelial neoplasia. The occurrence of squamous epithelium in inflammatory cloacogenic polyps is to be expected, given the site of these lesions. The extent of the surface squamous component in the polyp we have described, together with the apparent replacement of superficial cryptal columnar epithelium by squamous epithelium in both reported cases associated with anal intraepithelial neoplasia, suggests that this may be in part a metaplastic process. This therefore raises further analogies with the predisposition to intraepithelial neoplasia provided by the unstable metaplastic squamous epithelium of the cervical transformation zone. Based on just two cases, however, we do not feel that further aetiopathogenic extrapolation is justified.

In their study of women with grade 3 cervical intraepithelial neoplasia, Scholefield et al found histological evidence of concomitant anal intraepithelial neoplasia in $19 \%$ of the cases ${ }^{6}$ the majority being of high grade, suggesting the potential importance of colposcopic anal examination in this population.

Whether the anal intraepithelial neoplasia in our case is an isolated finding or represents a manifestation of more extensive anal canal disease has yet to be determined clinically.

This case of anal intraepithelial neoplasia in an inflammatory cloacogenic polyp emphasises the importance of histological examination of all perianal lesions, even in young adults. It also highlights the role of colposcopic surveillance, to include both genital and perianal regions, in the further management of such patients.

We thank Mrs P Lofthouse for preparation of the manuscript.

1 Lobert PF, Appelman HD. Inflammatory cloacogenic polyp: a unique inflammatory lesion of the anal transitional zone. Am f Surg Pathol 1981;5:761-6.

2 Du Boulay CEH, Fairbrother J, Isaacson PG. Mucosal prolapse syndrome- - a unifying concept for solitary rectal ulcer syndrome and related disorders. F Clin Pathol 1983;36: $1264-8$

3 Saul SH. Inflammatory cloacogenic polyp: relationship to solitary rectal ulcer syndrome/mucosal prolapse and other bowel disorders. Hum Pathol 1987;18:1120-5.

4 Frisch $\mathrm{M}$, Olsen JH, Bautz A, et al. Benign anal lesions and the risk of anal cancer. N Engl f Med 1994;331:300-2.

5 Foust RL, Dean PJ, Stoler MH, et al. Intraepithelial neoplasia of the anal canal in haemorrhoidal tissue. Hum Pathol 1991;22:528-34.

6 Scholefield JH, Hickson WGE, Smith JHF, et al. Anal intraepithelial neoplasia: part of a multifocal disease process. Lancet 1992;340:1271-3. 